\title{
A small solitary fibrous tumor of the bladder
}

\author{
Guido Petracco, Carlo Patriarca
}

Division of Surgical Pathology, Azienda Ospedaliera Sant'Anna, Via Ravona, San Fermo d/B, 22020 Como, Italy.

Correspondence to: Dr. Carlo Patriarca, Division of Surgical Pathology, Azienda Ospedaliera Sant’Anna, Via Ravona, San Fermo d/B, 22020

Como, Italy. E-mail: carlo.patriarca@hsacomo.org

How to cite this article: Petracco G, Patriarca C. A small solitary fibrous tumor of the bladder. J Cancer Metastasis Treat 2016;2:388-90.

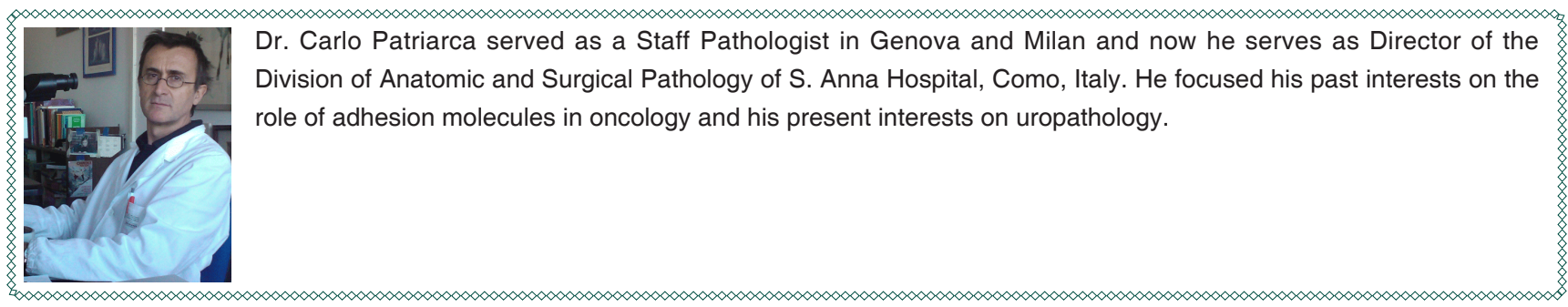

Article history:

Received: 28-04-2016

Accepted: 06-07-2016

Published: 30-09-2016

Key words:

Solitary fibrous tumor,

bladder,

small

\begin{abstract}
The authors present a case of histologically benign and incidentally discovered millimetric solitary fibrous tumor of the bladder, invisible to radiologic imaging and clinically benign. The case came to our attention because of repeated episodes of renal colic. As opposed to the present case, solitary fibrous tumor are generally discovered when they reach certain dimensions, being slow-growing, painless masses. Such a tumor of the bladder is a very rare finding, with less than 20 cases reported, and it has yet to be described with such a small size. The main differential diagnoses are discussed. Such tumors with histological features of malignancy are also described in the literature. However, the present case had a bland appearance so a conservative approach with an excision was adopted. No signs of recurrence are present at follow-up.
\end{abstract}

\section{INTRODUCTION}

Solitary fibrous tumor (SFT) is a rare type of mesenchymal tumor described in the years originally as hemangiopericytoma, later as SFT. ${ }^{[1-3]} \mathrm{A}$ malignant histology has been also described in different organs. ${ }^{[4]}$ Nevertheless, SFT involving the urinary bladder is a very rare finding. We present one case of bladder primary SFT of a few millimeters, incidentally discovered.

\section{CASE REPORT}

A 72-year-old male patient with repeated episodes of renal colic was admitted to the emergency room of our

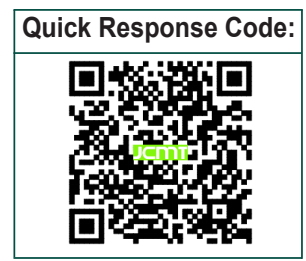


hospital. He underwent an echographic investigation that showed only grade 1-2 hydronephrosis. Moreover, leucocytosis and elevated C-reactive protein was observed. An expulsion therapy was performed.

After 1 week, a computed tomography scan showed hydronephrosis with a $10 \mathrm{~mm} \times 8 \mathrm{~mm}$ ureteral calculus located $4 \mathrm{~cm}$ from the bladder neck. The patient underwent an endoscopic lithotripsy. During the procedure, a $4 \mathrm{~mm}$ bladder nodule was seen on the mucosa surface, thus removed by the urologist and submitted for histologic examination.

This showed a mesenchymal proliferation with low cellularity [Figure 1], without atypia [Figure 2] and a mitotic index below $1 / 10$ high power field. Immunohistochemistry demonstrated strong CD34 positivity [Figure 3], weak B cell lymphoma (BCL2)

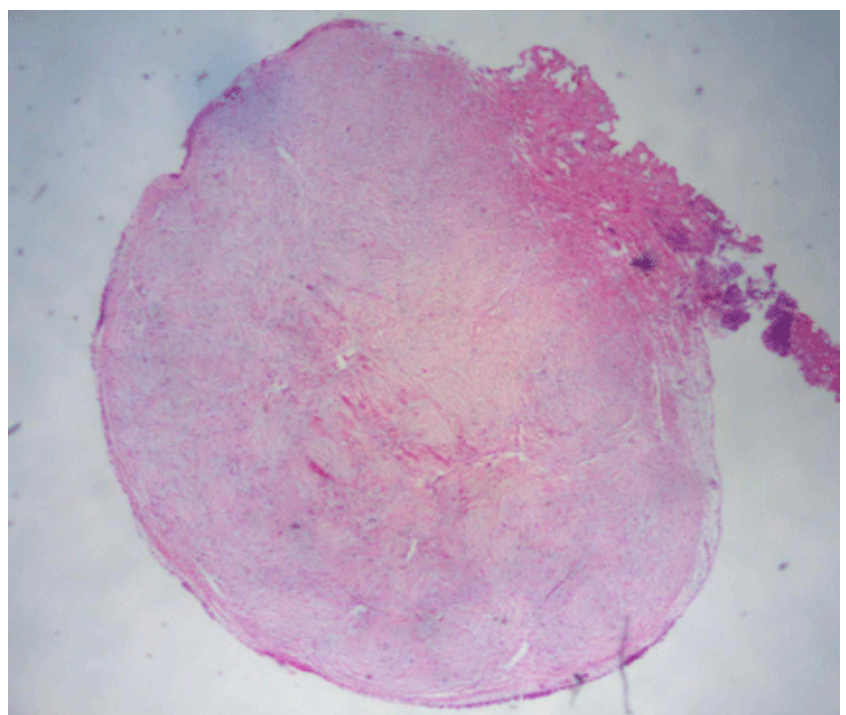

Figure 1: Nodular, small solitary fibrous tumor of bladder mucosa. Complete excision was performed $(\mathrm{HE}, \times 10)$

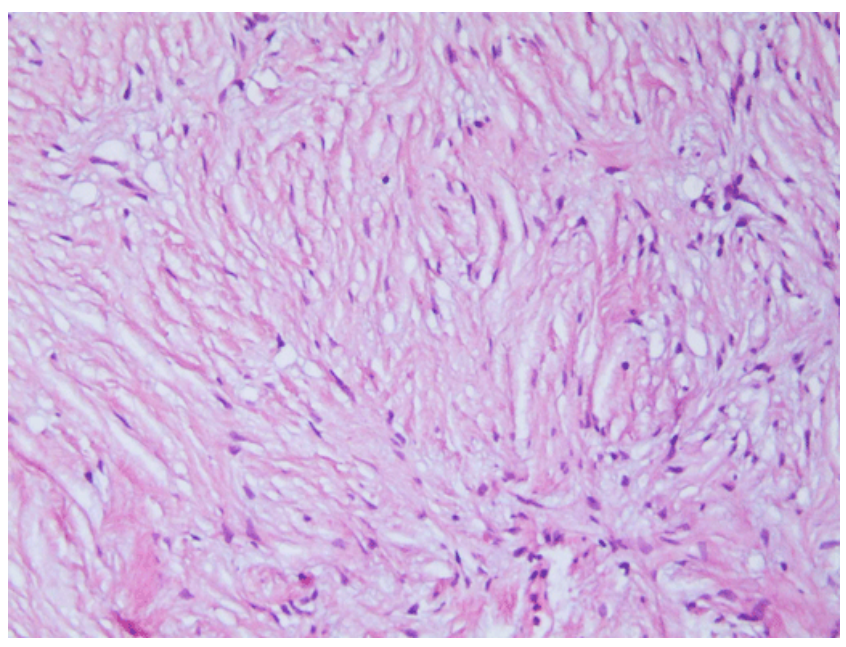

Figure 2: Mesenchymal proliferation with low cellularity, without atypia, and without mitotic activity $(\mathrm{HE}, \times 40)$

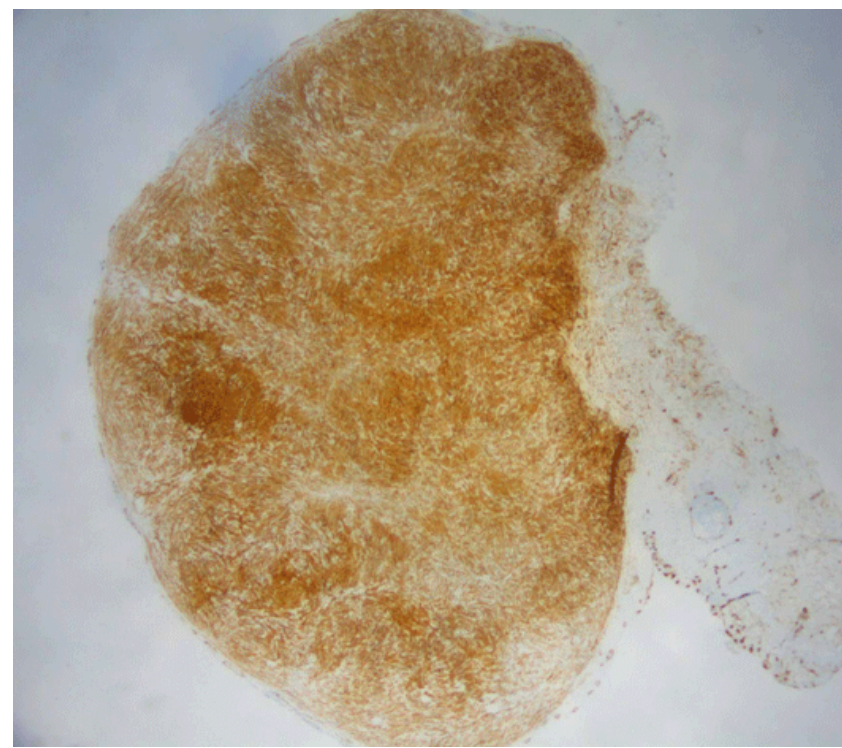

Figure 3: CD34: strong, diffuse immunostaining of entire lesion (ABC perox, $\times 10)$

positivity, and negativity for both $\mathrm{S} 100$ and smooth muscle actin. Hence, a diagnosis of solitary fibrous tumor was formulated.

Among the differential diagnoses, inflammatory fibroblastic tumor was ruled out because of poor cellularity, activin receptor-like kinase 1 (ALK1) negativity, and absence of an inflammatory component. Likewise, spindle cell nodule and benign neoplasms such as leiomyoma or neurofibroma were excluded for morphophenotipic features. Ten months after excision the patient had no ecographic sign of recurrence.

\section{DISCUSSION}

Extrapleural SFTs are anatomically ubiquitous, as documented also by the present case report, and occur equally in males and females, primarily in adult life, with a wide range of ages, 20 to 70 years..$^{[4,5]}$ The ubiquity of SFT supports its mesenchymal origin (with fibroblastic/myofibroblastic features). ${ }^{[3]}$ Most present as a slow-growing, painless masses. In cases of bladder SFT, the most frequent symptoms, such as pain, palpable mass, abdominal distention, urinary retention, haematuria, constipation, and bowel obstruction, are related to compression and local invasion of nearby structures.

In the English literature 15 cases have been reported, ${ }^{[6,8-11]}$ all with symptoms related to tumor volume (up to $12 \mathrm{~cm}$ in diameter), and presence of radiologic findings. ${ }^{[12-16]}$ Sometimes, a diagnosis of malignant soft tissue tumor was considered. Actual malignant bladder SFT has been described, ${ }^{[7]}$ while to the best of our knowledge, this is the first case of a 


\section{SFT of just $4 \mathrm{~mm}$.}

The World Health Organization classification of tumors of soft tissue in 2013 identifies the SFTs among the tumors with a rarely unpredictable behavior ${ }^{[17]}$ Indeed, although most cases are slow-growing and benign, behavior can sometimes be aggressive and distant metastasis may occur. ${ }^{[5]}$ However, features more frequently related with a poor prognosis are tumor size over $10 \mathrm{~cm}$, malignant histology such as high mitotic count and necrosis, while the feature more frequently related with local recurrence is the presence of positive surgical margins if resectability is difficult. ${ }^{[11]}$

This is the first description of a very small, subcentimeter SFT reported in the literature. Since, in our case, no malignant characteristics were present, a conservative approach after an endoscopic complete resection was adopted. Currently the patient is being followed but without recurrence.

\section{Financial support and sponsorship}

Nil.

\section{Conflicts of interest}

There are no conflicts of interest.

\section{Patient consent Obtained.}

\section{Ethics approval}

Ethics approval was obtained prior to the commencement of the study.

\section{REFERENCES}

1. Wagner E. Das tuberkelahnliche lymphadenom (der cytogene oder reticulirte tuberkel). Arch Heilk (Leipzig) 1870;11:497.

2. Klemperer P, Coleman BR. Primary neoplasms of the pleura. A report of five cases. Arch Pathol 1931;11:385.

3. Chan JK. Solitary fibrous tumor -- everywhere, and a diagnosis in vogue. Histopathology 1997;31:568-76.

4. Mosquera JM, Fletcher CD. Expanding the spectrum of malignant progression in solitary fibrous tumors: a study of 8 cases with a discrete anaplastic component--is this dedifferentiated SFT? Am J Surg Pathol 2009;33:1314-21.

5. Goldblum JR, Folpe AL, Weiss SW, Enzinger FM. Enzinger and Weiss's soft tissue tumors, 6th ed. Philadelphia, PA: Saunders/ Elsevier, 2014. p. 1002-14.

6. Heinzelbecker J, Becker F, Pflugmann T, Friemann J, Walz PH. Solitary fibrous tumour of the urinary bladder in a young woman presenting with haemodynamic-relevant gross haematuria. Eur Urol 2008;54:1188-91.

7. Dozier J, Jameel Z, McCain DA, Hassoun P, Bamboat ZM. Massive malignant solitary fibrous tumor arising from the bladder serosa: a case report. J Med Case Rep 2015;9:46.

8. Mozafarpour S, Khorramirouz R, Tajali A, Salavati A, Kajbafzadeh AM. Surgically treated bladder hemangiopericytoma/solitary fibrous tumor: report of a 12-year asymptomatic follow-up. Int Urol Nephrol 2014;46:483-6.

9. Tzelepi V, Zolota V, Batistatou A, Fokaefs E. Solitary fibrous tumor of the urinary bladder: report of a case with long-term follow-up and review of the literature. Eur Rev Med Pharmacol Sci 2007;11:101-6.

10. Leite KR, Srougi M, Miotto A, Camara-Lopes LH. Solitary fibrous tumor in bladder wall. Int Braz J Urol 2004;30:406-9.

11. Bruzzone A, Varaldo M, Ferrarazzo C, Tunesi G, Mencoboni M. Solitary fibrous tumor. Rare Tumors 2010;2:e64.

12. Wang T, Chen R, Qiao J, Hu T, Liu J, Yang W, Ye Z. Solitary fibrous tumor in bladder: a case report. J Huazhong Univ Sci Technolog Med Sci 2010;30:412-4.

13. Kibar Y, Uzar AI, Erdemir F, Ozcan A, Coban H, Seckin B. Hemangiopericytoma arising from the wall of the urinary bladder. Int Urol Nephrol 2006;38:243-5.

14. Westra WH, Grenko RT, Epstein J. Solitary fibrous tumor of the lower urogenital tract: a report of five cases involving the seminal vesicles, urinary bladder, and prostate. Hum Pathol 2000;31:63-8.

15. Otta RJ, Acosta MA, Gordillo C. A rare case of solitary fibrous tumour of the bladder. Can Urol Assoc J 2014;8:E552-3.

16. Kim SH, Cha KB, Choi YD, Cho NH. Solitary fibrous tumor of the urinary bladder. Yonsei Med J 2004;45:573-6.

17. Fletcher CDM, Bridge JA, Hogendoorn PCW, Mertens F. WHO classification of tumors of soft tissue and bone. Lyon: IARC Press, 2013. 